\title{
To Deepen the Supervision In the Enterprise Operation And Management of the Practice and Exploration
}

\author{
Li Rong Gao \\ Tianjin Light Industry Vocational Technical College 300350
}

\section{Key words: Enterprise management; The supervision; Practice; Experience}

\begin{abstract}
In the process of enterprise management, the supervision work belongs to the enterprise management of the supervision and management work, can to the enterprise operation and management of a certain role, will be once again to the enterprise operation and management of management and supervision, again can effectively improve the management efficiency of enterprises and promote the further development of the enterprise. The supervision in the process of enterprise management occupies a certain position, affecting the enterprise supervision and management of the operating efficiency of the effect, to the enterprise operation and management of in-depth the supervision is necessary, and it is also a necessary choice of modern enterprise management. This paper, according to the theory of enterprise management to deepen the supervision of the corresponding analysis on the practice and explore, continuously improve enterprise management level and promote the modernization development of the enterprise.
\end{abstract}

Under the influence of economic globalization, the enterprise want to in the invincible position in the intense market competition, to improve enterprise's own management level and promote the further development of the enterprise. In the process of enterprise operation and management, the supervision is to ensure normal operation of enterprise supervision and management of the guarantee and foundation. The deepening of the supervision, effectively improve the efficiency of enterprise operation and management, truly implement supervision and administration of the enterprise. Continuously improve enterprise management level and quality, promote the further development of the enterprise. But, in the actual work for supervising enterprise efficiency, staff awareness of efficiency supervision is not enough in-depth, and law enforcement is not enough, to a certain extent, affected the supervisory work of enterprise efficiency. Therefore, we need to deepen the supervision work in the enterprise management practice of in-depth analysis and exploration, then constantly improve the management level of enterprises and promote the further development of the enterprise.

\section{The supervision of the relevant overview}

So-called effectiveness supervision, mainly refers to in the process of enterprise operation and management work, quickly found the problem and timely remedy and stop, relevant systems and regulations continuously improve enterprise management, improve enterprise operation and management of the "law enforcement", to ensure the progress of the enterprise management. In the process of enterprise operation and management, the supervision work mainly for the comprehensive supervision and management process of the enterprise. Such not only can guarantee the normal work of the supervision and administration of enterprises, but also to the enterprise operation and management to provide the corresponding services, improve the level and quality of enterprise management. In the process of enterprise supervision and management work, the supervision work belongs to a kind of administrative supervision, can produce certain effect to enterprise's operation and management. To deepen the supervision, not only can improve the level and quality of enterprise management, but also can avoid such as illegal behavior within the enterprise, improve enterprise's overall effectiveness. At the same time, to deepen the supervision, can help enterprises to a certain extent, reduce the enterprise investment operation cost, also can enhance the enterprise ability to predict the risk of investment. This not only for the further 
development of the enterprise to bring the corresponding economic benefits, more social benefit for the further development of the enterprise, continuously improve enterprise management level, ensure the safety of the enterprise production and operation process, gradually realize the modernization development of the enterprise.

\section{The necessity of deepening the supervision in enterprise management}

2.1Deepen the supervision function. In the process of enterprise supervision and management work, the supervision can not only to the enterprise worker individual conduct supervision, but also to the enterprise overall management of the status monitoring, can effectively improve enterprise management level and quality. Supervision and administration of the enterprise has a certain binding and punitive. Through the supervision, to the risk problem in the enterprise operation and management of effective prevention, can also to the illegal behavior of enterprise interior existence for effective check and supervision, improving the efficiency of enterprise supervision and management work. Deepen the supervision at the same time, it can be aimed at weak links that exist in the process of enterprise operation and management for real-time monitoring, and to guide education, supervision and management, deepening enterprise supervision function, promote the effectiveness of supervisory work smoothly.

2.2To do a good job of preventing. Can deepen the supervision, aiming at various problems in the process of enterprise operation and management of prevention and management, reduce the risk of enterprise operation and management. In the process of deepening the supervision, every enterprise management work must comply with the relevant rules and regulations, has certain regularity, put an end to any corruption within the enterprise. Set up perfect the supervision mechanism, intensify law enforcement, truly "laws, the laws," constantly standard enterprise management work, improve work efficiency and quality of enterprise management.

2.3Provide safeguards. To deepen the supervision, to ensure that the enterprise will be the country's policies and regulations to implement, also in the process of enterprise management rules and regulations to supervise and check, ensure the smooth operation of the enterprise efficiency supervisory work. Deepen the supervision of the enterprise, is to implement national policy and implementation, to ensure the normal operation of enterprise management work, to provide a good external environment for the further development of the enterprise.

\section{To deepen the supervision in the enterprise operation and management of the practice}

3.1According to the enterprise actual situation to carry out the supervision. In the enterprise in the process of deepening the supervision, according to the actual situation, the development of the enterprise has the feasibility and effectiveness of supervision work, combined with modern information technology and network technology, within the enterprise to establish a set of systematic, the differentiation of the supervision network platform. Expanding channels for supervising enterprise efficiency, in the enterprise internal form a kind of mutual supervision and network system, so as to really play the role of supervision, improve the level for supervising enterprise efficiency, promote the further development of the enterprise.

3.2Continuously improve the effectiveness of existing enterprise supervision mechanism. As the saying goes: "no can be accomplished without norms or standards", in the process of enterprise management, in order to get a good supervision and management efficiency, it is necessary to establish the corresponding supervision mechanism, ensure enterprise supervision and management work smoothly. Deepen the work for supervising enterprise efficiency, need to set up a complete and systematic efficiency of supervision mechanism. In the process of the actual effectiveness supervision, truly "laws", ensure the normal running of the supervision work. At the same time, in the process of develop the supervision mechanism, also on the rule of law education propaganda work, strengthen the consciousness of legal system for enterprise employees, guide enterprise employees actively involved in the enterprise management activities, so as to improve the level and quality of enterprise management work. 
3.3Coordinate internal functional departments from the view of development. With the continuous development of the socialist market economy, the enterprises to gain great development, it needs to coordinate the relationship between the various functional departments within the enterprise. The various functional departments to plan as a whole, for the supervision and internal control management, such ability in the supervision of the enterprise internal form a good atmosphere, to ensure that the enterprise supervision and management work smoothly. To deepen the process of the supervision, with a view of the development of the problem, in the enterprise internal form a kind of "force", so as to ensure the quality of enterprise management.

3.4Strengthen supervision learning to deepen enterprise efficiency. In the process of the actual effectiveness supervision, due to the supervision work involves wide, prosecutors should not only grasp the technical knowledge, and to master practical knowledge, but also to master the knowledge of the policy, so as to ensure the smooth progress of the supervision work. Supervisory personnel need to be constantly learning, therefore, enterprises must regularly to supervisory personnel training, for the further development of the enterprise training more applied interdisciplinary talents with professional ability and professional accomplishment, promote the further development of the enterprise.

\section{Conclusion:}

To sum up, deepen the supervision in the enterprise management, can effectively improve the management level of enterprises, to carry out the enterprise supervision and management work, promote the further development of enterprise management. In the process of deepening the supervision and inspection department should according to the actual operating conditions of enterprises, to carry out targeted and effectiveness of supervision, improve the efficiency of the enterprise existing supervision mechanism and ensure enterprise efficiency supervisory work smoothly. At the same time, with a view of the development of the enterprise of the relationship between the various functional departments, scientific and reasonable to coordinate the relationship between the various functional departments, to strengthen learning, constantly improve enterprise efficiency supervision level and quality, promote the further development of enterprise management.

\section{References:}

[1] Sun Xiaofeng. Our local government administrative efficiency supervision development present situation and countermeasure analysis [D]. Heilongjiang university, 2015:1-56.

[2] Qi Genchang. A company effectiveness supervision existing problems and countermeasures research [D]. East China university of science and technology, 2016:1-63.

[3] Liang Xiuhua. Enterprises to deepen the supervision measures and experience [J]. Journal of enterprise reform and management, 2014 (11).

[4] Yang Yanhua, Liu Huifa, Cao Xiaomao, Cai Shouye, Hu Yuanwei, Guo Libin. Deepen reform innovation mechanism - Henan energy chemical group practice "six integration" management personnel management mode [A]. Modern large-scale coal enterprise management classic case (human resources) [C], 2013:12. 